\title{
Characterization and Inflammatory Response of Perivascular- Resident Macrophage-Like Melanocytes in the Vestibular System
}

\author{
Fei Zhang, ${ }^{1}$ Jinhui Zhang, ${ }^{1}$ Lingling Neng, ${ }^{1}$ and Xiaorui Shi ${ }^{1}$ \\ ${ }^{1}$ Oregon Hearing Research Center, NRC04, Department of Otolaryngology/Head and Neck Surgery, Oregon Health and Science \\ University, Portland, OR 97239, USA
}

Received: 26 April 2013; Accepted: 13 June 2013; Online publication: 3 July 2013

\begin{abstract}
A large number of perivascular cells expressing both macrophage and melanocyte characteristics (named perivascular-resident macrophage-like melanocytes, $\mathrm{PVM} / \mathrm{Ms}$ ), previously found in the intra-strial fluidblood barrier, are also found in the blood-labyrinth barrier area of the vestibular system in normal adult cochlea, including in the three ampullae of the semicircular canals (posterior, superior, and horizontal), utricle, and saccule. The cells were identified as $\mathrm{PVM} / \mathrm{Ms}$, positive for the macrophage and melanocyte marker proteins F4/80 and GST $\alpha 4$. Similar to $\mathrm{PVM} / \mathrm{Ms}$ present in the stria vascularis, the PVM/Ms in the vestibular system are closely associated with microvessels and structurally intertwined with endothelial cells and pericytes, with a density in normal (unstimulated) utricle of $225 \pm 43 / \mathrm{mm}^{2}$; saccule $191 \pm$ $25 / \mathrm{mm}^{2}$; horizontal ampullae $212 \pm 36 / \mathrm{mm}^{2}$; anterior ampullae $238 \pm 36 / \mathrm{mm}^{2}$; and posterior ampullae $223 \pm$ $64 / \mathrm{mm}^{2}$. Injection of bacterial lipopolysaccharide into the middle ear through the tympanic membrane causes the $\mathrm{PVM} / \mathrm{Ms}$ to activate and arrange in an irregular pattern along capillary walls in all regions within a 48-h period. The inflammatory response significantly increases vascular permeability and leakage. The results underscore the morphological complexity of the blood barrier in the vestibular system, with its surrounding basal lamina, pericytes, as well as second
\end{abstract}

Correspondence to: Xiaorui Shi - Oregon Hearing Research Center, NRC04, Department of Otolaryngology/Head and Neck Surgery . Oregon Health and Science University - Portland, OR 97239, USA. Telephone: +1-503-4947149; fax: +1-503-4945656; email: shix@ohsu.edu line of defense in PVM/Ms. PVM/Ms may be important to maintain blood barrier integrity and initiating local inflammatory response in the vestibular system.

Keywords: mouse vestibular system, perivascularresident macrophage-type melanocyte, inflammation, vascular permeability

\section{INTRODUCTION}

Perivascular-resident macrophages in the brain, retina, and other tissues (Cuadros and Navascues 1998; Kezic and McMenamin 2008; Guth et al. 2009; Brigitte et al. 2010; Yang et al. 2010) play a role in immunological defense and repair (Cui et al. 2009; Ekdahl et al. 2009). The resident macrophages scavenge invading microorganisms and dead cells (Mitrasinovic and Murphy 2002; Mitrasinovic et al. 2005; Nimmerjahn et al. 2005). The resident macrophages are also immuneeffector cells that produce superoxide anions, nitric oxide, and inflammatory cytokines during inflammation (Block and Hong 2005; Block et al. 2007; Hanisch and Kettenmann 2007; Cheret et al. 2008).

A large number of perivascular cells which express both macrophage and melanocyte characteristics (perivascular-resident macrophage-like melanocytes, $\mathrm{PVM} / \mathrm{Ms}$ ) are previously found in the intra-strial fluid-blood barrier (Shi, 2010; Zhang et al. 2012). Using double-label fluorescent immunohistochemistry, combined with confocal microscopy, we also found a population of PVM/Ms in the vestibular system, including in horizontal, anterior, and posterior 
semicircular canal ampullae, utricle, saccule, and semicircular canal. In an earlier study, we demonstrated that $\mathrm{PVM} / \mathrm{Ms}$ are a hybrid cell type, with morphology and function similar to astrocytes in the blood-brain barrier and glial cells in the blood-retina barrier (Zhang et al. 2012), playing an essential role in regulation of the intrastrial fluid-blood barrier integrity by affecting the expression of tight and adherens junction proteins. In the absence of PVM/Ms, the permeability of the endothelial cell monolayer markedly increases (Zhang et al. 2012). Expression of specific macrophage surface markers and scavenger receptors in strial PVM/Ms is also indicative of their contribution to maintenance and repair of the intra-strial fluid-blood barrier under conditions of tissue injury and inflammation (Shi 2010).

In this study, we characterized $\mathrm{PVM} / \mathrm{M}$ phenotype, density, and function in the blood-labyrinth barrier of the normal adult vestibular system, particularly under inflammatory conditions. The cells were verified as $\mathrm{PVM} / \mathrm{Ms}$ by positive immunolabeling for the specific cell surface makers, F4/80 and GST $\alpha 4$. The vestibular $\mathrm{PVM} / \mathrm{Ms}$, like strial PVM/Ms, closely associated with microvessels and intertwined with endothelial cells and pericytes. The functional role of the vestibular $\mathrm{PVM} / \mathrm{Ms}$ was especially apparent under inflammatory conditions. Injection with bacterial lipopolysaccharide (LPS) through the tympanic membrane in normal C57BL/6J adult mice caused activation and irregularities in the PVM/Ms, asymmetric positioning along capillary walls in all regions, and a significant increase vascular permeability and leakage within a 48-h period.

\section{MATERIALS AND METHODS}

\section{Animals}

Male C57BL/6J mice (aged 4-6 weeks, stock number 000664) were purchased from Jackson Laboratory (Bar Harbor, ME, USA). The protocol for the care and use of these animals was approved by the Institutional Animal Care and Use Committee at Oregon Health and Science University (IACUC approval number MU7_IS00001157).

\section{Immunohistochemistry}

In this study, mice were first deeply sedated with ketamine hydrochloride $(100 \mathrm{mg} / \mathrm{kg}$, intramuscularly) and $2 \%$ xylazine hydrochloride $(10 \mathrm{mg} / \mathrm{kg}$, Abbott Laboratories, USA). The mice were perfused intravascularly via the left ventricle with phosphate-buffered saline (PBS, $\mathrm{pH} 7.4$ ), followed by the fixative $4 \%$ paraformaldehyde. The mice were then sacrificed by decapitation, and their cochleae were harvested. The cochleae were then perilymphatically perfused with the same fixative and the vestibular system tissues isolated and placed in PBS with $4 \%$ paraformaldehyde overnight. After being washed in PBS, tissue samples were permeabilized in $0.5 \%$ Triton X-100 (Sigma, USA) for $1 \mathrm{~h}$ and immunoblocked with a solution of $10 \%$ goat serum (alternatively rat or rabbit serum) and $1 \%$ bovine albumin in $0.02 \mathrm{~mol} / \mathrm{L}$ PBS for an additional hour. The specimens were incubated overnight at $4{ }^{\circ} \mathrm{C}$ with the primary antibodies (Table 1) diluted in PBS-bovine serum albumin (BSA). After several washes in PBS, the samples were incubated with secondary antibodies (Table 1 ) for $1 \mathrm{~h}$ at room temperature. Capillaries were labeled with lectin Griffonia simplicifolia IB4 (GS-IB4) conjugated to Alexa Fluor 568. The tissues were washed for $30 \mathrm{~min}$, mounted (H-1000, Vector Laboratories, USA), and visualized under an FV1000 Olympus laser-scanning confocal microscope. Controls were prepared by replacing primary antibodies with overnight incubation in PBS-BSA.

\section{Assessment of vascular permeability}

Vascular permeability in control and LPS-treated cohorts was assessed using a fluorescein isothiocyanate (FITC)-conjugated bovine albumin tracer (FITCalbumin, $\sim 66 \mathrm{kDa}, \mathrm{A}-9771$, Sigma, USA). The tracer was intravenously administered to the tail vein of anesthetized animals $30 \mathrm{~min}$ prior to harvesting. Anesthetized animals were perfused intravascularly through the left ventricle with Hank's balanced salt solution (HBSS). The mice were decapitated and whole mounts of the vestibular system imaged on a fluorescent microscope (Leica DM2500, Germany).

Vascular leakage in each group receiving FITCalbumin was quantitatively analyzed. The mice were anesthetized and perfused intravascularly for $5 \mathrm{~min}$ with HBSS. The vestibular system was then removed, homogenized in $1 \%$ Triton X-100 in PBS, and the lysate centrifuged at 16,000 rpm for $20 \mathrm{~min}$. Relative fluorescence of the supernatant was measured on a Tecan GENios Plus Microplate Reader (Tecan Group Ltd, USA), with samples for each group run in quintuplicate. Data were represented as means \pm SD.

For in situ detection, Alexa Fluor 568-conjugated goat anti-human IgG (molecular mass, $200 \mathrm{kDa}$ ) (A21090, Invitrogen, USA) was administered by i.v. for $2 \mathrm{~h}$. Anesthetized animals were perfused intravascularly through the left ventricle for 2 min with HBSS followed by 5 min of $4 \%$ paraformaldehyde (PFA) in PBS. The vestibular system from each group was removed and post-fixed overnight with $4 \%$ PFA in PBS, pH 7.2, at $4{ }^{\circ} \mathrm{C}$. Whole-mounted parts of the vestibular system were immunolabeled with anticollagen IV antibody (Table 1). Tissue samples were 
TABLE 1

\begin{tabular}{|c|c|c|c|c|c|}
\hline \multicolumn{6}{|c|}{ Primary and second antibodies employed } \\
\hline Antibodies & Vectors & Identification & Dilution & Source & Specificity \\
\hline GST $\alpha 4$ & $\begin{array}{l}\text { Santa Cruz } \\
\text { Biotechnology, } \\
\text { Santa Cruz, CA }\end{array}$ & Cat\# sc-241483 & $\begin{array}{l}\text { 1:50 (dilution with } \\
1 \% \text { BSA-PBS) }\end{array}$ & $\begin{array}{l}\text { Goat polyclonal } \\
\text { antibody }\end{array}$ & $\begin{array}{l}\text { Reacts with human, } \\
\text { mouse, bovine, and } \\
\text { porcine }\end{array}$ \\
\hline $\mathrm{F} 4 / 80$ & San Diego, CA & Cat\# 14-4801-85 & $\begin{array}{l}\text { 1:50 (dilution with } \\
1 \% \text { BSA-PBS) }\end{array}$ & $\begin{array}{l}\text { Rat monoclonal } \\
\text { antibody }\end{array}$ & Reacts with mouse \\
\hline Desmin & $\begin{array}{l}\text { Abcam, Cambridge, } \\
\text { MA }\end{array}$ & Cat\# Ab32362 & $\begin{array}{l}1: 100 \text { (dilution with } \\
1 \% \text { BSA-PBS) }\end{array}$ & $\begin{array}{l}\text { Rabbit monoclonal } \\
\text { antibody }\end{array}$ & $\begin{array}{l}\text { Reacts with mouse, rat, } \\
\text { guinea pig, and human }\end{array}$ \\
\hline Collagen IV & $\begin{array}{l}\text { Abcam, Cambridge, } \\
\text { MA }\end{array}$ & Cat\# Ab6586 & $\begin{array}{l}1: 100 \text { (dilution with } \\
1 \% \text { BSA-PBS) }\end{array}$ & $\begin{array}{l}\text { Rabbit polyclonal } \\
\text { antibody }\end{array}$ & $\begin{array}{l}\text { Reacts with mouse, rat, } \\
\text { cow, human, and pig }\end{array}$ \\
\hline $\begin{array}{l}\text { Isolectin GS-IB4-conjugated } \\
\text { Alexa Fluor } 568 \text { conjugate }\end{array}$ & $\begin{array}{l}\text { Invitrogen, } \\
\text { Eugene, OR }\end{array}$ & Cat\# 121411 & $\begin{array}{l}1: 100 \text { (dilution with } \\
1 \% \text { BSA-PBS) }\end{array}$ & Griffonia simplicifolia, & $\begin{array}{l}\text { Reacts with mouse and } \\
\text { bovine }\end{array}$ \\
\hline $\begin{array}{l}\text { Alexa Fluor 488-conjugated } \\
\text { goat anti-rabbit } \lg G\end{array}$ & $\begin{array}{l}\text { Invitrogen, } \\
\text { Eugene, OR }\end{array}$ & Cat\# A-11008 & $\begin{array}{l}1: 100 \text { (dilution with } \\
1 \% \text { BSA-PBS) }\end{array}$ & Goat & Reacts with rabbit \\
\hline $\begin{array}{l}\text { Alexa Fluor } 647 \text {-conjugated } \\
\text { goat anti-rabbit } \lg G\end{array}$ & $\begin{array}{l}\text { Invitrogen, } \\
\text { Eugene, OR }\end{array}$ & Cat\# A-21245 & $\begin{array}{l}1: 100 \text { (dilution with } \\
1 \% \text { BSA-PBS) }\end{array}$ & Goat & Reacts with rabbit \\
\hline $\begin{array}{l}\text { Alexa Fluor } 488 \text {-conjugated } \\
\text { goat anti-rat } \lg G\end{array}$ & $\begin{array}{l}\text { Invitrogen, } \\
\text { Eugene, OR }\end{array}$ & Cat\# A-11006 & $\begin{array}{l}1: 100 \text { (dilution with } \\
1 \% \text { BSA-PBS) }\end{array}$ & Goat & Reacts with rat \\
\hline $\begin{array}{l}\text { Alexa Fluor } 647 \text {-conjugated } \\
\text { goat anti-rat } \lg G\end{array}$ & $\begin{array}{l}\text { Invitrogen, } \\
\text { Eugene, OR }\end{array}$ & Cat\# A-21247 & $\begin{array}{l}1: 100 \text { (dilution with } \\
1 \% \text { BSA-PBS) }\end{array}$ & Goat & Reacts with rat \\
\hline $\begin{array}{l}\text { Alexa Fluor } 488 \text {-conjugated } \\
\text { rabbit anti-rat } \lg G\end{array}$ & $\begin{array}{l}\text { Invitrogen, } \\
\text { Eugene, OR }\end{array}$ & Cat\# A-21210 & $\begin{array}{l}1: 100 \text { (dilution with } \\
1 \% \text { BSA-PBS) }\end{array}$ & Rabbit & Reacts with rat \\
\hline $\begin{array}{l}\text { Alexa Fluor 568-conjugated } \\
\text { rabbit anti-goat } \lg G\end{array}$ & $\begin{array}{l}\text { Invitrogen, } \\
\text { Eugene, OR }\end{array}$ & Cat\# A-11079 & $\begin{array}{l}1: 100 \text { (dilution with } \\
1 \% \text { BSA-PBS) }\end{array}$ & Rabbit & Reacts with goat \\
\hline
\end{tabular}

imaged with an FV1000 Olympus laser-scanning confocal microscope.

\section{LPS treatment}

Animals in the LPS group were trans-tympanically injected with $10 \mu \mathrm{l}$ emulsion of LPS in $0.9 \%$ sodium chloride (LPS $5 \mathrm{mg} / \mathrm{ml}$, Sigma, USA). The LPS was injected into the middle ear cavity of the left ear for $48 \mathrm{~h}$.

\section{Counts of F4/80- and GST $\alpha 4$-positive cells}

Cells labeled with antibody for F4/80 or cells colabeled with antibodies for F4/80 and GST $\alpha 4$ in the vestibular system of control and LPS-treated mice (cohorts of five mice) were counted on a standard epifluorescence microscope with a $\times 20$ objective. Counts were obtained for ten randomly chosen, nonoverlapping $150 \times 300 \mu \mathrm{m}$ areas of each group, and the data were represented as means $\pm \mathrm{SD}$.

\section{Counts of F4/80- and GS-IB4-positive cells}

The percentage of active PVM/Ms was determined for whole mounts of semicircular canal ampullae, utricle, and saccule on control and LPS-treated groups (cohorts of five mice). Cells double labeled for F4/80 (green) and GS-IB4 (red) were counted on a fluorescence confocal microscope with a $\times 20$ objective. The percentage of double-labeled cells was identified by color: green for cells showing green only labeling for F4/80 and yellow for cells positive for both markers F4/80 and GS-IB4. The percentage was calculated as:

Number of cells positive for both F4/80 and GS-IB4 per $\mathrm{mm}^{2}$

Number of cells positive for $\mathrm{F} 4 / 80$ per $\mathrm{mm}^{2}$ $\times 100 \%$.

\section{Statistics}

All statistical analyses were performed using SPSS 17.0. Data, presented as means $\pm \mathrm{SD}$, were evaluated using Student's $t$ test for group comparisons. A $95 \%$ confidence level was considered statistically significant. 


\section{RESULTS}

Identification of perivascular-resident macrophages in the vestibular system

The peripheral vestibular system consists of different end organs including the semicircular canals, utricle, saccule, and three ampullae (Fig. 1A, B). Using fluorescent immunohistochemical labeling for F4/ 80 , combined with confocal microscopy, we found a population of dendrite-shaped resident macrophages with ramified processes (green) distributed in different regions of the vestibular system of normal adult cochlea, but particularly concentrated in capillary regions labeled by GS-IB4 (red) (Fig. 1C).

\section{Perivascular-resident macrophages identified as melanocytes}

Double-label immunofluorescence showed F4/80-positive cells to express melanocyte marker protein, including cytosolic GST $\alpha 4$ (Fig. 2A-C). The resident macrophages contain melanin pigment granules in the cytoplasm (Fig. 2D-F). The data indicate that resident macrophages are a hybrid cell type, differing from the classical macrophage, having both macrophage and melanocyte characteristics, thus the moniker, perivascular-resident macrophage-like melanocytes.

Perivascular-resident macrophage-like melanocytes are in close contact with capillaries

The PVM/Ms, highly invested on the abluminal surface of capillaries and structurally intertwined with endothelial cells, have dendritic processes that interface with the capillary wall. Whole-mounted semicircular canal ampullae, utricle, saccule, and semicircular canal triple labeled for F4/80, desmin, and GS-IB4 to show PVM/Ms (blue) closely associated with pericytes (green) and endothelial cells (red). The three cell types structurally intertwine. The left panels of Figure 3 show the distribution of the three cell types under low-magnification differential interference contrast (DIC) and confocal fluorescence microscopy. The middle and right panels of Figure 3 are low- and high-magnification confocal images which show PVM/Ms adjacently associated with pericytes and endothelial cells.

\section{LPS treatment induces inflammation}

The density of F4/80-positive cells in normal (unstimulated) utricle was $225 \pm 43 / \mathrm{mm}^{2}$; saccule 191 $\pm 25 / \mathrm{mm}^{2}$; horizontal ampullae $212 \pm 36 / \mathrm{mm}^{2}$; anterior ampullae $238 \pm 36 / \mathrm{mm}^{2}$; and posterior ampullae $223 \pm 64 / \mathrm{mm}^{2}$ (Fig. 4A). Injection of LPS $(5 \mathrm{mg} / \mathrm{ml})$ into the middle ear through the tympanic membrane causes a dramatic and statistically significant increase in F4/80-positive cells in all regions within a 48-h period (Fig. 4B). Comparison of F4/80-positive cells in the control and LPS-treated groups is shown in Figure 4C. However, it should also be remarked that approximately $20-40 \%$ of the F4/80-positive cells are not positive for melanocyte marker proteins GST $\alpha 4$ (Fig. 4D), suggesting macrophage infiltration into the vestibular system due to the inflammation.

\section{LPS treatment causes PVM/M activation}

Activated macrophages display terminal galactopyranosyl group on their membrane surface which binds GS-IB4. Enhanced affinity and binding of lectins to GS-IB4 is well-developed as a marker for macrophage activation (Takacs and Staehli 1987;
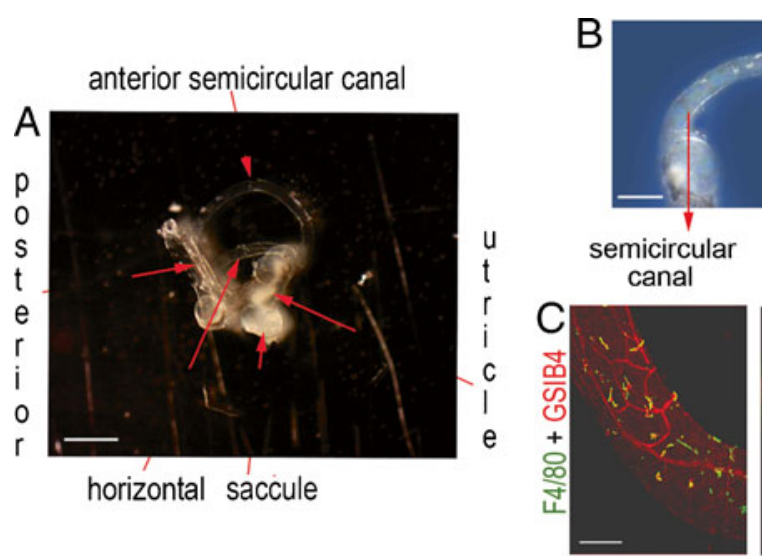

FIG. 1. Perivascular-resident macrophage in the vestibular system. A shows a macroview of an isolated mouse vestibular system. The scale bar is $1,000 \mu \mathrm{m}$. B Different parts of the normal vestibular system, including the horizontal, anterior, and posterior semicircular canal ampullae, utricle, saccule, and semicircular canal are photo-

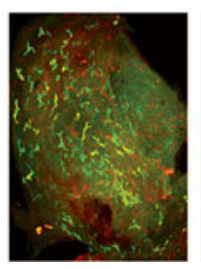

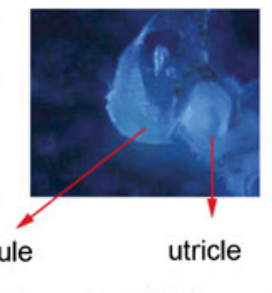
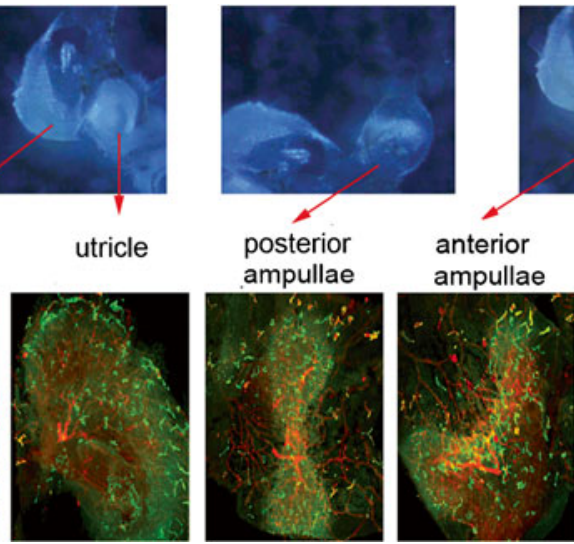

graphically portrayed. The scale bar is $500 \mu \mathrm{m}$. C PVM/Ms in different parts of the normal vestibular system are labeled with antibody for F4/80 (green), with capillaries labeled by GS-IB4 (red). The scale bar is $100 \mu \mathrm{m}$. 

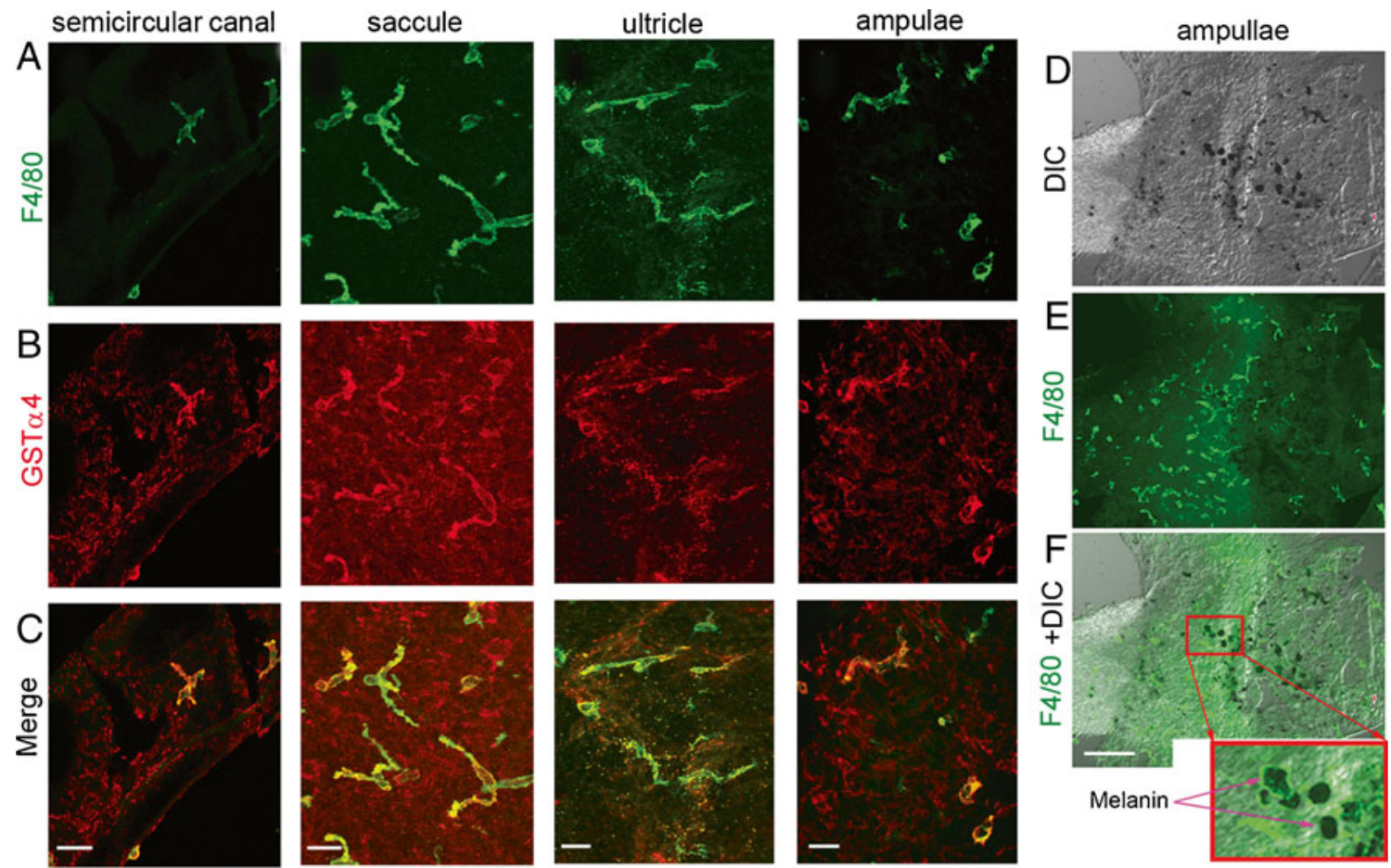

FIG. 2. Perivascular-resident cells identified as melanocyte-like macrophages. A-C PVM/Ms double labeled with antibody for F4/80 and GST $\alpha 4$ show positive staining for macrophage and melanocyte marker proteins F4/80 (green) and GSTa4 (red). The scale bar is

$50 \mu \mathrm{m}$. D-F PVM/Ms contain melanin pigment granules. The column-reticular square region in panel $\mathbf{F}$ shows melanin granules under a high magnification. The scale bar is $100 \mu \mathrm{m}$.

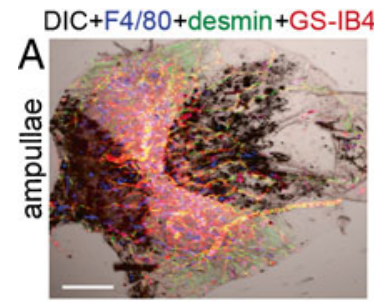

$\mathrm{F} 4 / 80+$ desmin+GS-IB4
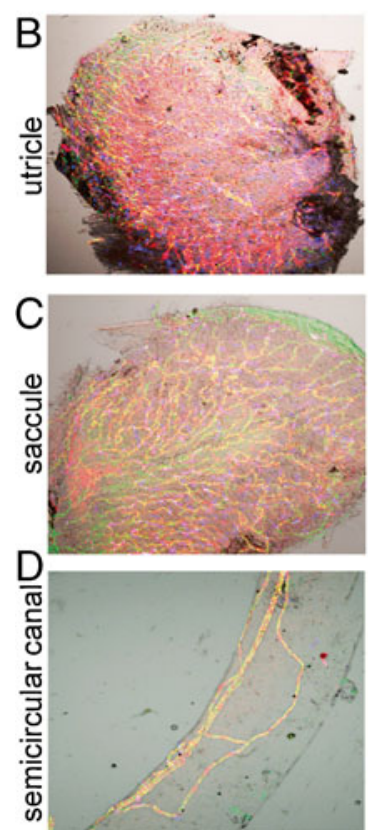

$\mathrm{F} 4 / 80+$ desmin+GS-IB4
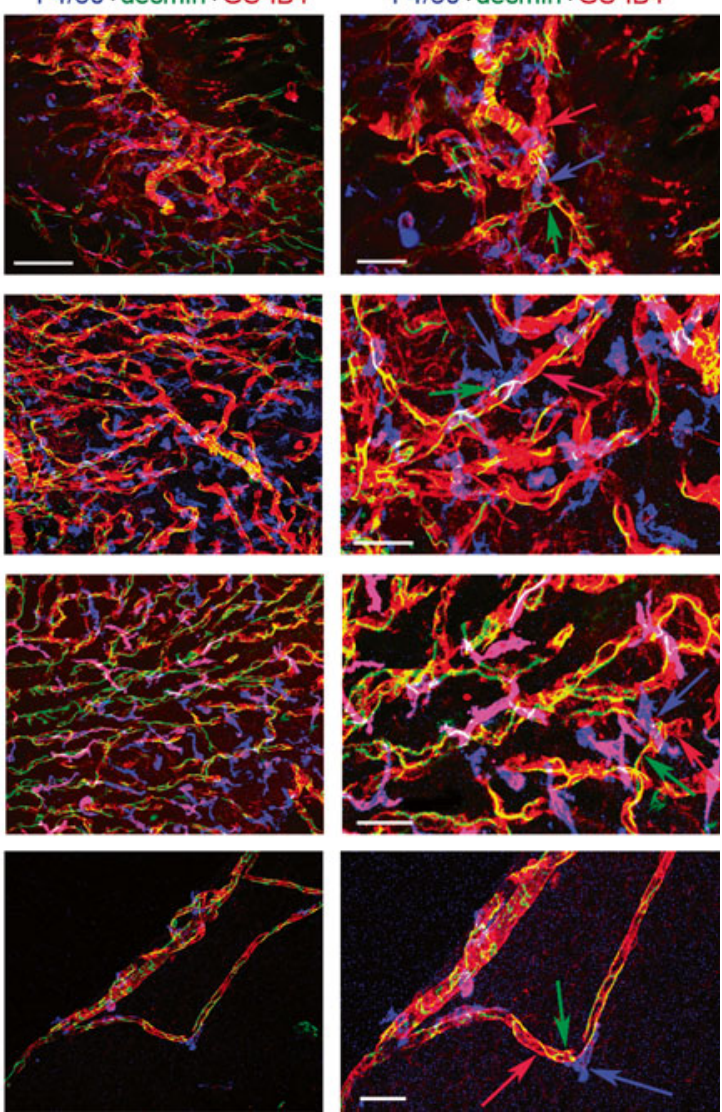
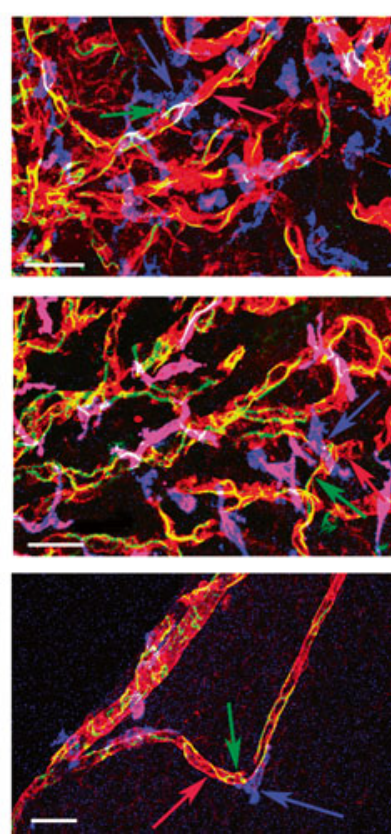

FIG. 3. PVM/Ms in the vestibular system are closely associated with microvessels and structurally intertwined with endothelial cells and pericytes. A-D (left panels) Whole-mounted semicircular canal ampullae, utricle, saccule, and semicircular canal triple labeled for F4/ 80 (blue), desmin (green), and GS-IB4 $(r e d)$ in low magnification $(\times 20)$ confocal and DIC images show PVM/Ms, pericytes, and endothelial cells. The scale bar is $100 \mu \mathrm{m}$. A-D (middle panels) The confocal image under higher magnification $(\times 40)$ shows the interaction between the three cell types. The scale bar is $50 \mu \mathrm{m}$. A-D (right panels) The zoomed image shows the three cell types to structurally intertwine. The scale bar is $30 \mu \mathrm{m}$. 

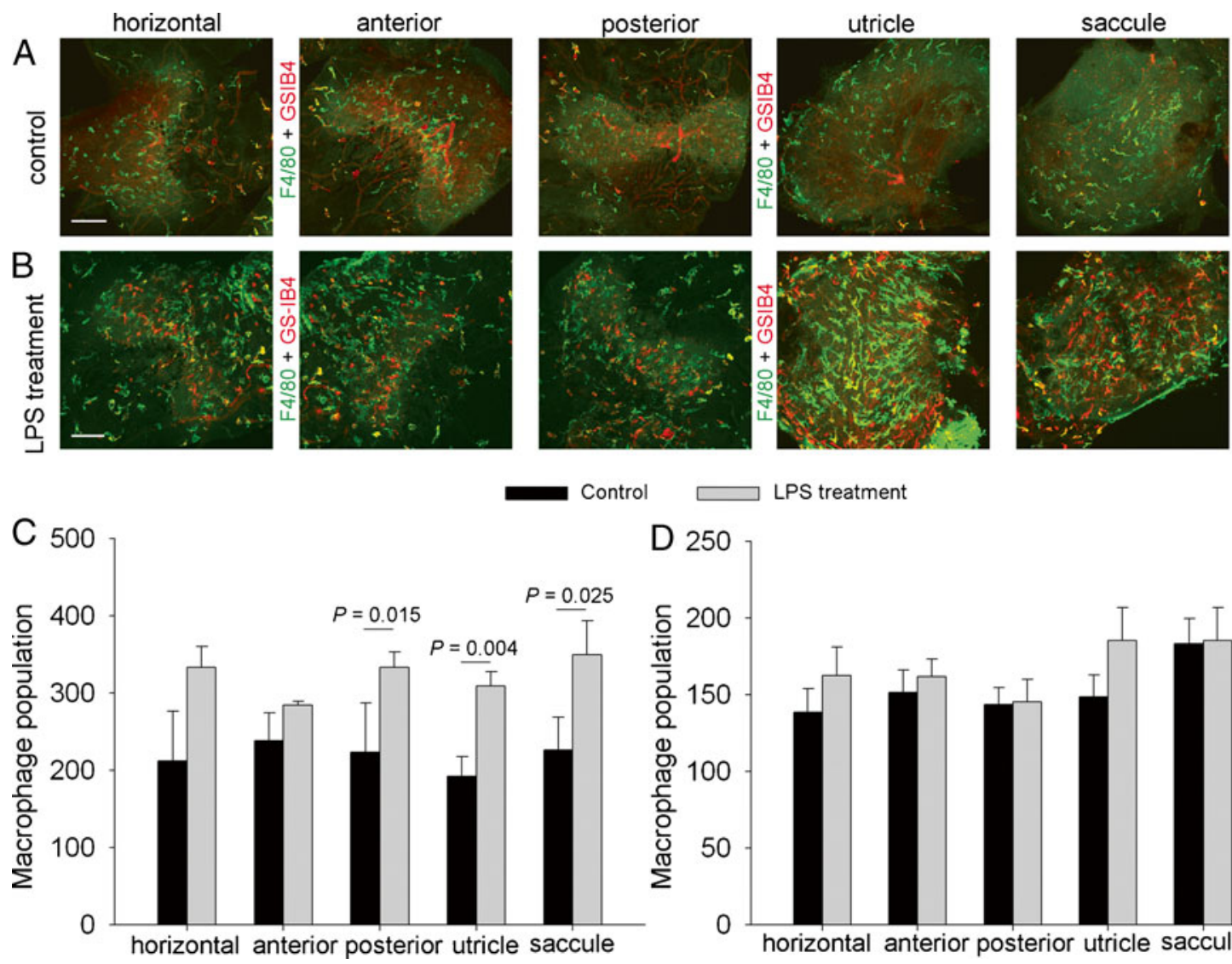

FIG. 4. LPS treatment causes inflammation. A, B Wholemounted semicircular canal ampullae, utricle, and saccule double labeled for F4/80 (green) and GS-IB4 (red) in the control (A) and LPS-treated groups (B). The scale bar is $100 \mu \mathrm{m}$. C, D F4/80-positive macrophage population in whole-mounted semicircular canal ampullae, utricle, and saccule is significantly

Tabor et al. 1989). In control tissue, most PVM/Ms do not bind GS-IB4 (Fig. 5A), and only 14-16\% are positively labeled. However, a significantly increased proportion of PVM/Ms are GS-IB4 positive in the LPStreated animals (Fig. 5B), with 80 to $84 \%$ of PVM/Ms in treated tissues GS-IB4 positive (Fig. 5C).

\section{LPS treatment increases vascular leakage}

Under normal conditions, the blood-fluid barrier restricts movement of large molecules, and to a lesser extent small molecules, into the ear (Fig. 6A). The barrier becomes highly permeable to large substances such as albumin-FITC and IgG Alexa Fluro-568 with $48 \mathrm{~h}$ of LPS treatment. When albumin-FITC is administered through the animal's tail vein $30 \mathrm{~min}$ prior to harvesting, fluorescent tracer accumulation is seen in isolated whole mounts of the vestibular system from leakage of the albumin-FITC $(\sim 66 \mathrm{kDa})$ (Fig. 6B). LPS-treated animals show significant leakage of albumin-FITC across the fluid-blood barrier
(Fig. 6C). Immunohistochemical staining in combination with confocal microscopy shows extravasation of high molecular weight IgG Alexa Fluro-568 tracers in tissues of LPS-treated animals (Fig. 6D-G). The data show inflammation to cause increased vascular permeability.

\section{DISCUSSION}

This study shows the vestibular system to contain a large population of PVM/Ms. By confocal imaging, the PVM/Ms are shown to be closely associated with microvessels and structurally intertwined with endothelial cells and pericytes. PVM/Ms in all regions of the vestibular system show marked activation and rearrangement into an irregular pattern with LPS treatment. The concurrent inflammatory response significantly increases vascular permeability and leakage. 


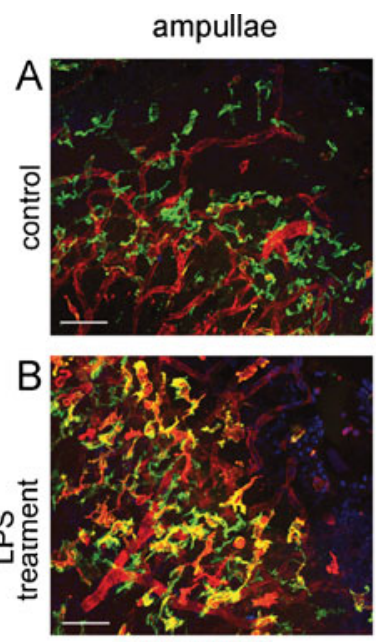

F4/80+GS-IB4

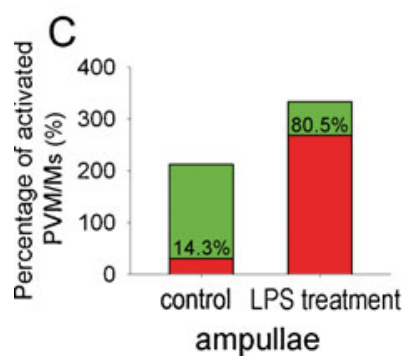

In a previous study, we found a large population of perivascular cells in the vicinity of the intra-strial fluid-blood barrier in the stria vascularis of normal adult cochlea. The cells were identified as perivascular-resident macrophages, positive for several macrophage surface molecules including $\mathrm{F} 4 / 80$, CD68, and CD11b (Shi 2010). Further study demonstrated the PVM/Ms to be a hybrid cell type, differing from the classical macrophage. In the present study, we have expanded our study to include the vestibular system and have investigated the morphological complexity of the blood barrier in the vestibular system, including its surrounding basal lamina, pericytes, as well as second line of defense in PVM/ Ms.

Resident dendritic cells or macrophages in most tissues have a physiological role which supports homeostasis (Lech et al. 2012). Perivascular-resident macrophages are prevalent in the brain, retina, lung, and intestine (Cuadros and Navascues 1998; Kezic and McMenamin 2008; Guth et al. 2009; Brigitte et al. 2010; Yang et al. 2010) where they have several important homeostatic roles. For example, macrophages are specialized for phagocytic clearance of airborne and ingested pathogens in the lung (Guth et al. 2009; Soroosh et al. 2013) and liver (Yang et al. 2012).

The phenotype and density of mononuclear phagocytes in different tissues vary widely, paralleling the wide range of homeostatic requirements in
FIG. 5. LPS treatment causes activation of PVM/Ms. A, B The PVM/Ms are activated by LPS treatment. Double-labeled whole-mounted ampullae, saccule, and utricle show PVM/Ms labeled with antibody for F4/80 also positive for GSIB4 in the LPS-treated groups. The scale bar is $50 \mu \mathrm{m}$. C, Percentage of activated PVM/Ms in ampullae, utricle and saccule" after 50 um.

$$
\text { saccule }
$$

different tissues. In a normal animal ear vestibular system, PVM/Ms are a hybrid cell type, expressing macrophage and melanocyte marker proteins, including F4/80 and cytosolic GST $\alpha 4$ (Fig. 2), and containing melanin pigment granules in the cytoplasm. Density of the cells across different regions of the vestibular system ranges between 191 and 238 $\pm 36 /$ $\mathrm{mm}^{2}$. The PVM/Ms are found invested on the abluminal surface of capillaries and intertwined with endothelial cells and dendritic processes at the interface with the capillary wall.

Tissue-resident macrophages are mobilized with trauma, as well as by pathogens and toxic insults to tissue homeostasis (Kharraz et al. 2013). In this study, injection of bacterial LPS into the middle ear through the tympanic membrane causes a dramatic increase in infiltration of inflammatory cells (with a significant increase in F4/80-positive cells). The PVM/Ms display marked morphological changes with increased binding to GS-IB4. High fluorescence signals for Alexa Fluor-conjugated GS-IB4 are seen in LPS-treated $\mathrm{PVM} / \mathrm{Ms}$ (Fig. 5), suggesting the PVM/Ms harbor a terminal galactopyranosyl group on their membrane surface (Maddox et al. 1982). Enhanced affinity for binding this lectin is well recognized as a marker to indicate the degree of macrophage responsiveness with exposure to various stimuli (Adams and Hamilton 1984; Tabor et al. 1989). Consistent with Maddox et al. (1982), we show that activated macrophages express terminal alinked galactopyranosyl residues on their surface which, 


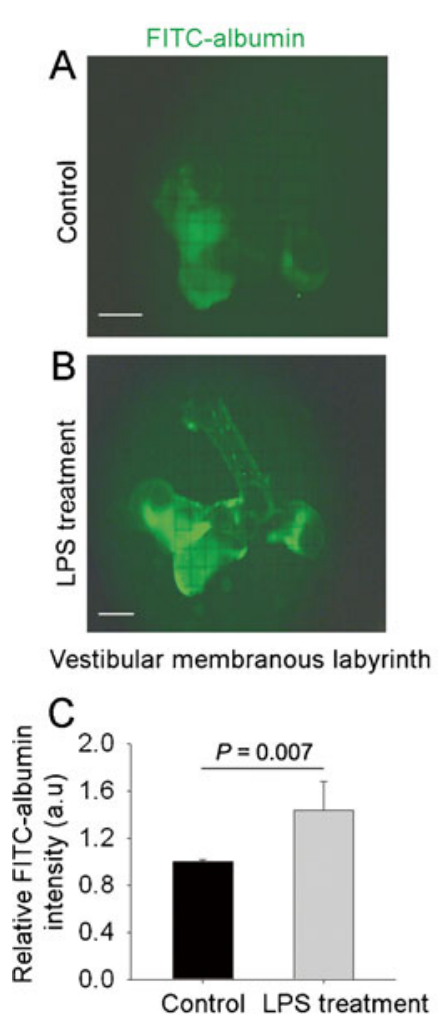

FIG. 6. LPS treatment increases vascular leakage. A, B Intravenously injected tracer (FITC-albumin, MW=66 kD) accumulates throughout the entire vestibular system of LPS-treated animals (B), but not in controls (A). C Capillary leakage of FITC-albumin is significant in LPS-treated mice $\left[n=6, P_{\text {(control vs LPS treatment) }}=0.007\right]$.

conversely, are not found on normal unstimulated macrophages (Fig. 5). Local phagocyte activation augments homeostasis, and the activation of $\mathrm{PVM} / \mathrm{Ms}$ in the vascular wall of the blood-labyrinth barrier may be the primary contributing factor in local inflammatory response.

$\mathrm{PVM} / \mathrm{Ms}$ are in close contact with vessels in the intra-strial barrier. Like astrocytes and glial cells in the brain, $\mathrm{PVM} / \mathrm{Ms}$ in the cochlea have an essential role in regulating barrier integrity and performing other tissue-oriented functions (Prat et al. 2001; Abbott et al. 2006). PVM/Ms in the intra-strial fluid-blood barrier affect membrane integrity by regulating synthesis of tight junction proteins, and loss of $\mathrm{PVM} / \mathrm{Ms}$ is associated with tissue edema (Zhang et al. 2012). $\mathrm{PVM} /$ Ms produce pigment epithelium growth factor, a $50-\mathrm{kDa}$ glycoprotein first identified in retinal pigment epithelium cells (Liu et al. 2012), which plays a role in the stria vascularis as an essential signaling molecule for stabilizing the intra-strial fluidblood barrier and establishing a normal hearing threshold (Zhang et al. 2012). The role of PVM/Ms in the blood barrier of the vestibular system may be similar to their role in the intra-strial fluid-blood
Collagen IV
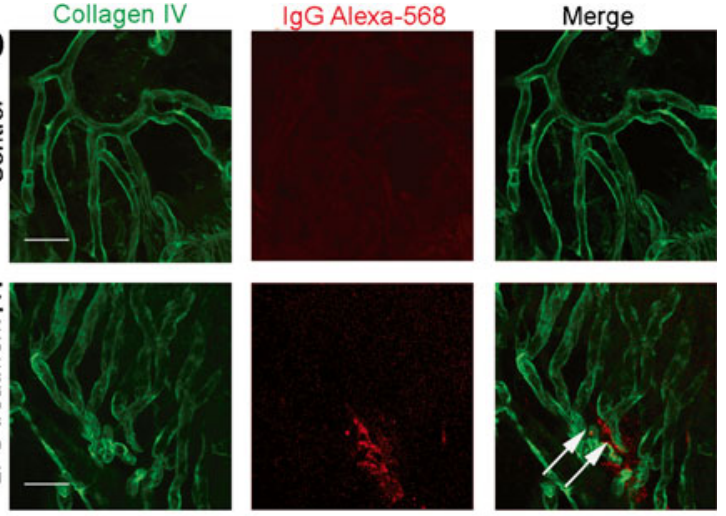

Collagen IV
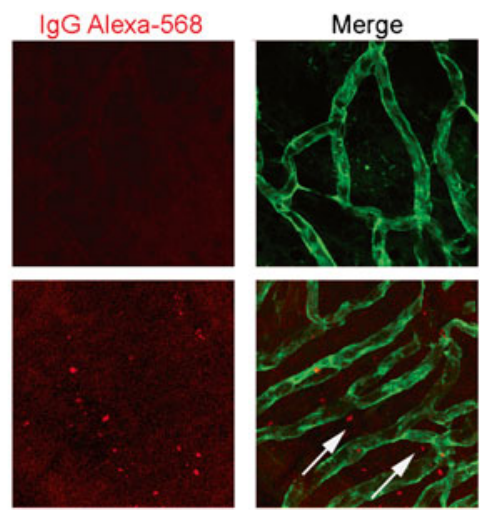

D-G Extravasation of intravenously injected IgG Alexa 568 (white arrows) from capillaries, visualized by collagen IV immunostaining (green), was observed in LPS-treated mice, but not in controls. The scale bar is $50 \mu \mathrm{m}$.

barrier. LPS treatment significantly increases vascular permeability and leakage in all regions and causes irregular arrangement of $\mathrm{PVM} / \mathrm{Ms}$ along capillary walls within a 48-h period.

Change in vascular architecture is known to be correlated with blood flow and vascular stability (Duvall and Robinson 1987). The rearrangement of PVM/Ms caused by the introduction of LPS toxin into the blood-labyrinth barrier may be related to the increased vascular leakage. Further studies are needed to identify the role of PVM/Ms in blood barrier permeability and for delineating the mechanisms of various inflammatory mediators and bacterial toxins in inducing vascular leakage.

\section{CONCLUSION}

A large number of PVM/Ms are found in the area of the blood-labyrinth barrier of the vestibular system in normal adult cochlea, including in the three ampullae of the semicircular canals (posterior, superior, and horizontal), utricle, and saccule. The cells are identified as PVM/Ms, as they are positive for the 
macrophage and melanocyte marker proteins, F4/80 and GST $\alpha$ 4. Similar to PVM/Ms present in the stria vascularis, the $\mathrm{PVM} / \mathrm{Ms}$ in the vestibular system are closely associated with microvessels and structurally intertwined with endothelial cells and pericytes. Tympanic injection of bacterial LPS into the middle ear causes dramatic infiltration of macrophages and irregular rearrangement of resident macrophages (PVM/ Ms) along capillary walls within a 48-h period. The inflammatory response significantly increases vascular permeability and leakage. The results indicate PVM/Ms in the vascular wall of the blood-labyrinth barrier may be important factors in maintaining blood barrier integrity and initiating local inflammatory response in the vestibular system.

\section{ACKNOWLEDGMENTS}

This work was supported by the National Institutes of Health grants NIH NIDCD R01-DC010844 (XS), DC R21DC1239801 (XS), and NIHP30-DC005983.

Open Access This article is distributed under the terms of the Creative Commons Attribution License which permits any use, distribution, and reproduction in any medium, provided the original author(s) and the source are credited.

\section{REFERENCES}

Aвbott NJ, Ronnback L, Hansson E (2006) Astrocyte-endothelial interactions at the blood-brain barrier. Nat Rev Neurosci 7:4153

Adams DO, Hamilton TA (1984) The cell biology of macrophage activation. Annu Rev Immunol 2:283-318

Block ML, Hong JS (2005) Microglia and inflammation-mediated neurodegeneration: multiple triggers with a common mechanism. Prog Neurobiol 76:77-98

Block ML, Zecca L, Hong JS (2007) Microglia-mediated neurotoxicity: uncovering the molecular mechanisms. Nat Rev Neurosci 8:57-69

Brigitte M, Schilte C, Plonquet A, Baba-Amer Y, Henri A, Charlier C, Tajbakhsh S, Albert M, Gherardi RK, Chretien F (2010) Muscle resident macrophages control the immune cell reaction in a mouse model of notexin-induced myoinjury. Arthritis Rheum 62:268-279

Cheret C, Gervais A, Lelli A, Colin C, Amar L, Ravassard P, Mallet J, Cumano A, Krause KH, Mallat M (2008) Neurotoxic activation of microglia is promoted by a nox1-dependent NADPH oxidase. J Neurosci 28:12039-12051

Cuadros MA, Navascues J (1998) The origin and differentiation of microglial cells during development. Prog Neurobiol 56:173-189

Cui Q Yin Y, Benowitz LI (2009) The role of macrophages in optic nerve regeneration. Neuroscience 158:1039-1048

Duvall AJ 3RD, Robinson KS (1987) Local vs systemic effects of acoustic trauma on cochlear structure and transport. Arch Otolaryngol Head Neck Surg 113:1066-1071
Ekdahl CT, Kokaia Z, Lindvall O (2009) Brain inflammation and adult neurogenesis: the dual role of microglia. Neuroscience 158:1021-1029

Guth AM, Janssen WJ, Bosio CM, Crouch EC, Henson PM, Dow SW (2009) Lung environment determines unique phenotype of alveolar macrophages. Am J Physiol Lung Cell Mol Physiol 296:L936-L946

Hanisch UK, Kettenmann H (2007) Microglia: active sensor and versatile effector cells in the normal and pathologic brain. Nat Neurosci 10:1387-1394

Kezic J, McMenamin PG (2008) Differential turnover rates of monocyte-derived cells in varied ocular tissue microenvironments. J Leukoc Biol 84:721-729

Kharraz Y, Guerra J, Mann CJ, Serrano AL, Munoz-Canoves P (2013) Macrophage plasticity and the role of inflammation in skeletal muscle repair. Mediat Inflamm 2013:491497

Lech M, Grobmayr R, Weidenbusch M, Anders HJ (2012) Tissues use resident dendritic cells and macrophages to maintain homeostasis and to regain homeostasis upon tissue injury: the immunoregulatory role of changing tissue environments. Mediat Inflamm 2012:951390

Liu JT, Chen YL, Chen WC, Chen HY, Lin YW, Wang SH, Man KM, Wan HM, Yin WH, Liu PL, Chen YH (2012) Role of pigment epithelium-derived factor in stem/progenitor cell-associated neovascularization. J Biomed Biotechnol 2012:871272

Maddox DE, Shibata S, Goldstein IJ (1982) Stimulated macrophages express a new glycoprotein receptor reactive with Griffonia simplicifolia I-B4 isolectin. Proc Natl Acad Sci U S A 79:166-170

Mitrasinovic OM, Murphy GM JR (2002) Accelerated phagocytosis of amyloid-beta by mouse and human microglia overexpressing the macrophage colony-stimulating factor receptor. J Biol Chem 277:29889-29896

Mitrasinovic OM, Grattan A, Robinson CC, Lapustea NB, Poon C, Ryan H, Phong C, Murphy GM Jr (2005) Microglia overexpressing the macrophage colony-stimulating factor receptor are neuroprotective in a microglial-hippocampal organotypic coculture system. J Neurosci 25:4442-4451

Nimmerjahn A, Kirchioff F, Helmchen F (2005) Resting microglial cells are highly dynamic surveillants of brain parenchyma in vivo. Science 308:1314-1318

Prat A, Biernacki K, Wosik K, Antel JP (2001) Glial cell influence on the human blood-brain barrier. Glia 36:145-155

SHI X (2010) Resident macrophages in the cochlear blood-labyrinth barrier and their renewal via migration of bone-marrow-derived cells. Cell Tissue Res 342:21-30

Soroosh P, Doherty TA, Duan W, Mehta AK, Choi H, Adams YF, Mikulski Z, Khorram N, Rosenthal P, Broide DH, Croft M (2013) Lung-resident tissue macrophages generate Foxp3+ regulatory $\mathrm{T}$ cells and promote airway tolerance. J Exp Med 210:775-788

TABOR DR, LARRY CH, Jacobs RF (1989) Differential induction of macrophage GSIB4-binding activity. J Leukoc Biol 45:452-457

Takacs B, Staehli C (1987) Activated macrophages and antibodies against the plant lectin, GSI-B4, recognize the same tumorassociated structure (TAS). J Immunol 138:1999-2007

Yang I, Han SJ, Kaur G, Crane C, Parsa AT (2010) The role of microglia in central nervous system immunity and glioma immunology. J Clin Neurosci 17:6-10

Yang Q, Shi Y, He J, Chen Z (2012) The evolving story of macrophages in acute liver failure. Immunol Lett 147:1-9

Zhang W, Dai M, Fridberger A, Hassan A, Degagne J, Neng L, Zhang F, He W, Ren T, Trune D, Auer M, Shi X (2012) Perivascularresident macrophage-like melanocytes in the inner ear are essential for the integrity of the intrastrial fluid-blood barrier. Proc Natl Acad Sci U S A 109:10388-10393 